\title{
The Cognitive Aspects of the Study of Regional Onomastics
}

\author{
Olga Konstantinovna Andryuchshenko*, Gulnara Sejlbekovna Suyunova \\ and Sofja Sergeevna Tkachuk \\ Pavlodar State Pedagogical Institute, Pavlodar, The Republic of Kazakhstan; \\ olga_pav_pgpi@mail.ru
}

\begin{abstract}
The study is focused on the description of the cognitive aspects of the proper names system analysis, as well as the study of linguistic presentation of onomastic knowledge at all levels of language, which is carried out by means of onomastic categories and is known as the onomastic representation. The authors outline the history of formation of cognitive linguistics abroad and analyze methods of cognitive analysis of regional proper names. The article describes the anthroponymic concept as a unit of onomastic knowledge about man and properties thereof as well as the toponymic concept as a unit of onomastic knowledge of the spatial and geographic characteristics. The analysis of the major characteristics of linguocultural concepts in linguistic conceptology allows identifying the most important features thereof. Developing the ideas of the most important characteristics of linguo-cultural concepts, the authors identify the basic characteristics of onomastic concepts.
\end{abstract}

Keywords: Concept, Cognitive Linguistics, Linguistics, Onomastics, Regional

\section{Introduction}

The relevance of this work is proved by its inclusion in the circle of contemporary researches in the framework of anthropocentric paradigm at the junction of dialectology, onomastics and cognitive linguistics. At the beginning of the $21^{\text {st }}$ century the problems of linguistic conceptualization in linguistics have become evident and have rapidly drawn attention of scientists, as well as the study of the specifics of linguistic consciousness of individual languages speakers. The study of the problems of representation of onomastic knowledge in language coincides with the general trend in the contemporary cognitive studies in linguistics focused on the analysis of different kinds of interaction between cognitive and linguistic structures, understanding the issue of the relationship of language and extra-linguistic reality (E.
S. Kubryakova, Yu. S. Stepanova, N. N. Boldyrev, N. V. Vasilyeva, A. Wezhbitzkaya, C. Fillmore, V. Evans, W. Croft, A. Cruz, A. Chenki, T. Klozner et al. $)^{1-7}$.

The scientific world is currently facing the necessity in clarifying the issue on how proper names reflect the processes of learning and represent the phenomena of the surrounding world and language as a part of this world, which raises relevance of the study of onomastics from cognitive points of view.

The choice of the research subject is conditioned by the necessity in conducting a holistic study of onomastic concepts represented by Pavlodar city-related onomalexemes which has not yet been carried out. This study covers only a part of the vast field of Russian dialect-related proper names system because the authors limit the area of the study and types of proper names (personal names, surnames, toponyms). This limitation, however, allows

\footnotetext{
${ }^{*}$ Author for correspondence
} 
making conclusions concerning the basic parameters of the conceptual and linguistic worldview of the Russian language speakers of the given area.

The choice of the subject and the direction of study served as the basis for determining its main objective, i.e., to explore the onomastic units as a means of representation of a certain conceptual content.

The attainment of the set objectives was facilitated by the use of basic common philological provisions on the relationship and interaction of language and society, on the systematicity of language as a general principle of the organization of Russian onomastics, observation that language in general and the proper name in particular carries a reflective function, as well as the results of research of the dialect concept in cognitive language system (A. F. Losev, A. V. Superanskaya, V. A. Nikonov, E. M. Murzaev, N. I. Tolstoy, V. D. Bondaletov, M. V. Gorbanevsky, A. K. Matveyev, A. D. Shmelev, N. N. Boldyrev, M. E. Rut, M. Golomidova, E. L. Berezovich, A. A. Burykin, N. V. Vasilyev, I. S. Karabulatova, S. P. Vasileva et al).

The scientific novelty of the research lies in the fact that it establishes a theory of onomastic representation, focused on the study and description of the role of onomastic categories in objectification and classification of knowledge about the world in such variety thereof as onomastic knowledge. This is the first research to adopt the onomastics representation, onomastic concept. For the first time a theory of categorization of regional anthroponym system is proposed arranged in three levels implying various ways of structuring knowledge used in onomastics.

A newly established (in terms of theory and methods) methodology of development of regional onomastic material research is aimed at the study of onomastic concepts. This methodology involves the analysis of various areas of knowledge: About man (for anthroponymic vocabulary) or geographic location - for place-names. These areas serve as a source of formation of meanings of dialect-related, and in particular, onomastic units.

The proposed concept is based on the idea that the regional sphere of concepts of the Russian language proper names is formed by onomastic concepts that are the basis for the formation of onomastic categories.

The theoretical significance of the study lies in the rationale and application of the cognitive approach to the study of onomastic units in the language, in the future development of the theories of conceptualization and categorization.
Of theoretical importance is the development of the concept of the basic onomastic representation and the respective conceptual and terminological framework for the study of the principles of organization of a sphere of concepts of proper names and methods of representation there of.

\section{Literature Review}

Cognitive linguistics focused on the language as an instrument of organization, processing and transmission of information, is an approach to the analysis of natural language which appeared in the late 70's - early 80 's. Cognitive linguistics as an independent field of linguistics originates from the works of Western school linguists G. Lakoff, R. Lenekera, L. Talmy, C. Fillmore. The researches in this area were conducted by their colleagues and students, among which are J. Fauconnier, I. Svitser, M. Johnson, M. Turner, R. Gibbs, B. Croft, A. Goldberg, J. Taggy, L. Yandu, C. Rice, R. Maldonado, C. von Hook, D. Geererts, H. Kuykens. Ideas of cognitive linguistics in Western and Central Europe were picked up and developed by a number of scientists: R. Dirven, B. Rood-zka-Austin, D. Taylor, K. Singh, A. Verhagen, B. Lewandowska-Tomashchuk, P. Harder, G. Radden ${ }^{8}$.

Cognitive linguistics has over the past three decades developed into one of the more intensively developing areas of research in the framework of theoretical and descriptive linguistics, changing the status of a "revolutionary" to "conventional". It addresses most of the issues dealt with by general linguistics - from phonology and pragmatics to syntax and semantics, and has incorporated some aspects of such sciences as developmental psychology - language acquisition, neuropsychology - materialized mind, neurobiology - operation of mechanisms of thinking, social psychology - language in social interaction?.

Language is the material of cognitive linguistics research. According to the English scientist John Taylor, language is "an integral part of human knowledge and analysis of all phenomena in the language should be based on knowledge of the cognitive activity of man, i.e., cognitive linguistics, being study of knowledge obtained through language rather than the study of language itself. Learning a language is necessary in the light of what is known about thinking through a variety of research methods, whether an experiment, introspection or just everyday observation" ${ }^{\prime \prime}$.

The editors of the Cognitive Linguistics Research Journal provide the following definition of cognitive 
linguistics: Cognitive linguistics incorporates a wide range of issues and a number of interoperable theoretical approaches, which are based on a single idea that language as one of the sides of knowledge reflects the social, cultural, psychological, communicative and functional aspects and it can only be understood in the context of a realistic view of its acquisition, cognitive development and mental processes. It seeks to explain the structure of language through the concepts typical for other cognitive mechanisms to which it refers, in addition to its communicative function ${ }^{10}$.

The basic postulates of cognitive linguistics were formulated by D. Geererts and H. Kuykens as follows: The object of cognitive linguistics is language in its cognitive aspect, and the word "cognitive" in this case refers to the key role of intermediate knowledge-related structures in our interactions with the world around us. Language if viewed as a means of organizing, processing, and transferring of information, is regarded as a depository of global knowledge, a structured set of relevant categories which helps us to deal with the new acquired experience and save the information obtained in the past. This is reflected in three basic characteristics of cognitive linguistics: The primacy of semantics in linguistic analysis, stemming from the cognitive nature of language itself, which determines its main purpose being categorization of the world as reflected in the language meaning; encyclopedic features of linguistic meaning; perspectivist nature of linguistic meaning ${ }^{8}$.

Cognitive linguistics is a cluster of interoperable and complementary approaches ${ }^{8}$. Thus, three large areas of research are singled out within cognitive linguistics:

- Approaches to the study of grammar providing for language study at both the structural and institutional levels. These include cognitive grammar (R. Leneker, L. Talmy) and structural grammar (C. Fillmore, P. Kay, A. Goldberg, J. Lakoff, W. Croft, B. Bergen).

- Cognitive semantics which considers by means of language various aspects of human mental activity such as knowledge representation and meaning formation. Cognitive semantics involves the theory of conceptual metaphor (J. Lakoff and M. Johnson, R. Gibbs, M. Turner), ${ }^{11-14}$ the theory of mental spaces (J. Fauconnier, B. Dansayger, Sh. Coulson), ${ }^{15}$ the theory of conceptual integration (or mixing) (G. Fauconnier and M. Turner), as well as such approach as cognitive lexical semantics, in the framework of which the theory of fundamental polysemy and the theory of lexical concepts and cognitive models have been developed (B. Evans, A. Theiler) ${ }^{16}$.
- Integrated approach involving the solution of a problem through the use of research results of the two areas mentioned above (B. Evans, A. Theiler, I. Svitser et al. $)^{17-20}$.

\section{Methods}

The following main provisions served as the methodological base of the research:

- On the dominant role of anthropocentric principle in the organization of language (V. Humboldt, L. Weisberger, M. Muller, E. Sapir, B. Whorf, F. Boas et al).

- On the relationship between the conceptual space represented by knowledge units and semantic space represented by linguistic means (Y. S. Stepanov, V. G. Kostomarov, E. S. Kubryakova V. Z. Demyankov, N. N. Boldyrev, N. D. Burvikova, A. A. Zalevskaya, I. A. Sternin, Z. D. Popova and many more).

The provision on the relationship between conceptual and linguistic levels is used as the methodological basis for the study of onomastics and is one of the basic assumptions of the theory of onomastic representation. Onomastic sign represents language knowledge as part of the knowledge of the world that allows us to speak about onomastic categorical representation as a special way to structure conceptual content. A detailed review of methodological tools of philological urbanism is provided in the research work by G. S. Suyunova and O. K. Andryuchshenko ${ }^{21}$.

To achieve this goal and solve a number of specific problems the authors applied methods of conceptual analysis and cognitive modeling. The following traditional research methods were also used: Direct observation and description, etymological analysis used in correlation of regional proper names with the dialect-related lexical material.

This article is aimed at the analysis of linguistic representation of onomastic knowledge at all levels of language which is carried out using onomastic categories and is known as the onomastic representation. The term "onomastic representation" refers to a transfer of onomastic knowledge in the form of concepts (units of knowledge) and of units language (linguistic units).

The main provisions of the theory of representation of onomastic knowledge are applied to the linguistic material of Pavlodar region.

Addressing onomastics from a cognitive perspective is in line with the general logic of modern cognitive research in linguistics which are focused on the study 
of "the interrelation of linguistic forms with their cognitive analogs, and, above all, with certain structures of knowledge" (E. S. Kubryakova) and the study of the model of organization and processing of conceptual content in language. From cognitive approach perspective the subject of the study of onomastic is transferred from linguistic means to consideration of onomastic realities in terms of their participation in the formation of meaning, in the process of linguistic reflection and formation of types of knowledge of the world in such variety thereof as onomastic knowledge (N. V. Vasilyeva).

This necessitates studying proper names in the context of knowledge and reflection of an integrated system of onomastic knowledge. This approach is based on understanding of language as "a means of formation and expression of thought, storage and organization of knowledge in the human mind" (N. N. Boldyrev), the study of what onomastic knowledge is reflected in the typology of proper names.

Among the works placing in the focus of attention the fundamental issue of onomastics dealing with the meaning of proper name three areas can be identified cultural linguistic (V. G. Kostomarov, E. M. Vereshchagin, V. V. Vorobyov, N. D. Burvikova, G. D. Tomakhin, A. T. Khrolenko et al.), ethno-linguistic (N. I. Tolstoy, S. M. Tolstaya, M. M. Kopylenko, A. S. Gerd, E. L. Berezovich and many more) and psycholinguistic (I. S. Karabulatova).

The main task of cultural linguistics and ethnolinguistics in respect to onomastic material is the study and description of the mechanisms serving as the basis for the interaction of proper names as linguistic units with the cultural code semantics. The result of this mechanism is presentation of cultural semantics by proper names (E. I. Sjanova).

Recognizing the scientific potential of each of the areas, it should be noted that domestic linguists identify their own objectives in the study of proper names in each of the areas. The ethno-linguistic approach focuses on the representation of national-and-cultural identity in the structure of the linguistic sign. It is typical for ethnolinguistics to study language through the prism of human consciousness, mentality, domestic and ceremonial behavior, mythological concepts and creativity mythpoetic creation (N. I. Tolstoy, S. M. Tolstaya). "Ethno-linguistics' object is not a linguistic unit but a person, individual, his/her deeds and actions in his relation to language and through language" (A. S. Gerd).

As part of culturological area, interpretation of proper names does not cover the entire proper names system as a whole, but only selective proper names marked by the national culture and "having a special reputation" (E. L. Berezovich). In the works of the representatives of culturological area the major attention is paid to the consideration of proper names only in the synchronous aspect that prevents from uncovering the entire nature of onomastic processes within a single dynamic system. Thus, the ratio of synchrony and diachrony is impaired as a methodological reflection of the fundamental property of language being temporal dynamics, which is a manifestation of the historicity of the existence of proper names as one of the social factors. E. D. Polivanov emphasized that the possibility of transfer of language from one generation to the next is ensured by the nature of the "linguistic processes continuity" statistically dominating the dynamics of development.

The culturological approach provides for the use of the term "logoepisteme" which was first introduced by V. G. Kostomarov and N. D. Burvikova within the meaning of the onomastic sign (anthroponym or placename), requiring conceptualization at two levels: At the level of language and the level of culture. According to scientists, logoepisteme "is is a marginal sign, adequate understanding of which implies proper command of both the code (language) and the information transmitted by this code (culture)". Logoepisteme analysis is based on the following cognitive idea: The provision on the conceptual level as a uniform level of knowledge representation and universal basis of language. However, in fact, logoepisteme is an element of the word meaning and is localized in the language.

Proponents of the cognitive approach to onomastics consider the meaning of proper name "as a result of reflection of reality by human consciousness" (I. S. Karabulatova). The cognitive function of onomastic phenomena, according to M. V. Golomidova is manifested in involvement of proper names in human mental activity and ability to retain knowledge either of linguistic or encyclopedic nature.

The authors of this article analyze two main types of onomastic knowledge: Anthroponymic and that related to place-names. The unit of onomastic knowledge that defines the semantics of proper names in general is understood as an onomastic concept. The authors use the terms "anthroponymic concept" as a unit of onomastic knowledge of human being and its characteristics and "toponymic concept" as a unit of onomastic knowledge of spatial and geographic characteristics. The variety of onomastic concepts in the mind of a human being living 
in a certain area, i.e., a set of concepts of natural objects and linguistic concepts forms the sphere of proper name concepts.

The analysis of the major characteristics of linguocultural concepts in linguistic conceptology suggests identification of their main characteristics, including, according to V. I. Karasik and G. G. Slyshkin: The complexity of existence, mental nature, value, conditionality and lack of definition, variability, limitedness of consciousness of language speaker, three-component pattern, poly-appealing nature, multidimensionality, methodological openness and polyqualification potential. Developing the ideas of the most important characteristics of linguo-cultural concepts the authors identify the basic characteristics of onomastic concepts.

- The mentality of education. Onomastic concepts are formed within individual and collective consciousness; it is consciousness where a concept reflects the general and specific perception by a human being of objects of reality objectified in proper names and typified in semantic models.

- Worthiness. Specificity of the onomastic concept manifests itself in the reflection of the main value-related concepts in human consciousness (national identity, spiritual life, memory, "friend or foe"), the specific features which are implemented in onomastics.

- The complexity of existence. The onomastic concept is a special unit of encyclopedic and linguistic knowledge determining the semantics of proper names.

- Conservativism and relative variability. The onomastic concept has a stable structure, ensuring its uniform understanding within a particular area of knowledge.

- Most of the onomastic concepts are conservative and stable because they are assigned certain onomastic means of verbalization relevant to thinking and communication.

- It is the stability of the system of linguistic means of expression that makes them known and commonly used. Only a small number of onomastic concepts can be referred to as unstable when they serve the scope of individual thinking. The limitedness of consciousness of a native speaker suggests the existence of individual, collective, ethnic, cultural and human onomastic concepts.

- Poly-objectification. There are many ways of linguistic objectification of onomastic concepts. The same concept is verbalized in the language with the help of linguistic units of different levels. At the same time uniformity of linguistic formalization can be seen in respect of onomastic vocabulary which is used in the official communication. What is meant here is the phenomenon of standardization which provides for setting a single standard for certain categories: Standards for spelling, transcription, pronouncing, morphology, derivation (A. V. Superanskaya).

- Multi-classification. Onomastic concepts feature a clear classification by a number of reasons: by phenomena that are appositional thereto in the world, by subject matter, by language speakers, by types of discourse oriented either towards live oral speech or codification of literary language. This factor determines the definition of the boundaries of onomastic categories combining onomastic concepts and forms of their representation in the language.

- The multidimensionality. The onomastic concept is multidimensional. Expressing the conceptual content and modeling of this concept can be performed using traditional units of cognitive science (onoma-frame as a structured concept, conceptual metaphors, representation concepts, specific sensual image, and image of a subject).

Actualization of onomastic concepts is performed using a wide range of linguistic means, among which two major groups can be identified. Oriented towards the language system, onomastic concepts are represented primarily at grammatical and lexical level of language.

- Grammatical onimisation using support morphemes (affixation, pluralization, singularization), root morphemes (adding bases with or without a connecting vowel, fusion) and syntactic tools (formation of wordgroup names).

- Semantic onimisation (simple, metaphorical, metonymic, a hybrid). The choice of certain onoma-variant for representing an anthroponymic concept is conditioned by countervailing factors of social nature.

An important property of onomastic concepts is the fact that they are the basis for the formation of onomastic categories. The onomastic category is understood to be an association of proper names based on a common concept (name concept). Onomastic categories have the same character as other lexical categories, because language uses common cognitive mechanisms of categorization.

The anthroponymic concept underlies the anthroponymic category while the toponymic concept is the basis for toponymic category. Onomastic categories reflect the linguistic knowledge of a person, his/her operation of the language - the ability to use onomastic signs for naming objects of reality. On a conceptual level, the onomastic category combines a variety of observed and virtual names into something common, brings them 
under a single heading, under certain thematic classes of proper name that allows considering a variety of objects/ subjects as elements of the same category. Hence, it follows that the system onomastic knowledge determines the nature and structure of the onomastic categories.

For the authors, of fundamental importance is the fact that onomastic concepts forming a regional sphere of proper name concepts are closely linked to the dialectal concepts as a special type of knowledge about regional varieties of linguistic units, i.e., dialectal forms can serve as a means of representation of onomastic knowledge since dialectal concepts are marked in the regional sphere of proper name concepts and provide a conceptual basis for the emergence of oppositions at various language levels. Dialectal and onomastic concepts support structuring of knowledge about regions cultural and linguistic specificities thereof. In cases when an onomastic concept acquires linguistic expression in a regional proper name, such proper name actually represents onomastic knowledge itself and knowledge of dialect nature, i.e., regional proper name confirms and reflects the territorial differences in the onomastic system (phonological, derivational, lexical).

Proper names system of any language is composed of various linguistic material and exists in the form of lexical and morphological units which historically belong to different languages (elements of substrate, adstrate, literary language etc.), as well as various chronological states of the same language and various social-and-regional variants of language. Some part of the sphere of proper name concepts is represented by unmotivated onoma-lexemes. The main cause of emergence of unmotivated units of onomastic space is their borrowed nature. Availability in the proper names system of any language of borrowed place-names is an absolute linguistic universal, and the availability of borrowed anthroponyms is a statistical universal with a high degree of probability.

\section{Results}

As is evident from the available material, the sphere of generic name concepts is represented by lexemes featuring non-uniform variability, while the sphere of proper name concepts is largely represented by dialectal words and linguistic archaisms that are more stable and tend to persist without radical changes for quite a long time. The regularity and frequency of use of certain generic names in a standardized language and dialect speech allows them to move to the proper names system and serve as a sign to designate animate beings (humans and animals) and inanimate objects (terrain, water body). In this case, generic names begin to express the contents of onomastic concepts forming the sphere of proper name concepts. The resulting study highlights are as follows:

- Having become a proper name a word cannot unlink itself from the source which it originates from as it maintains a specific pool of certain conceptual features.

- Marked types of anthroponymic and toponymic knowledges suggest merging of various conceptual features that allow to conclude on that the structure of onomastic concepts specifies the way of representation thereof by identifying various conceptual characteristics: Human, Christianity, territory, "friend or foe", memory.

In our system of reasoning the sphere of proper name concepts serves as a means of storage and transfer of two types of knowledge: Non-linguistic knowledge about the world and its categories and the linguistic knowledge itself, knowledge of linguistic meanings and categories. The point at issue is that the proper name is a means of objectification of phenomena of reality, fulfilling the basic language functions (nominative, distinguishing and differentiating), it is the result of understanding reality.

In this regard, in the sphere of proper name concepts two aspects of ontology manifest themselves. First, the set of all groups of onomastic vocabulary (static aspect), i.e., its users have a common fund of knowledge. Secondly, the functioning of the units and their use in the statements (dynamic aspect), which serve as a means of encoding encyclopedic knowledge (the entire set of names in any onomastic space is alive in the memory of older village dwellers).

Regional proper names-related lexicon is by virtue of its specific nature to a greater extent represents the human's ability to "keep in mind" the use of various means of language, a set of his emotional and evaluative, and word-building tools. This results in onomastics conceptualization manifesting its specificity at all levels of language, creating a basis for consideration of onomastic representation as a special categorical method of representation of knowledge in a language.

\section{Discussion}

The content of this article was discussed at a scientific seminar of the Department of Russian Language and Literature of Pavlodar State Pedagogical Institute (Kazakhstan). Also, certain problems have been outlined 
by the authors in the materials of international scientific conferences and in journals recommended by the Committee for Control of Education and Science of the Ministry of Education and Science of the Republic of Kazakhstan.

Although opposite to the cognitive trend, the pragmatic and linguo-cultural trends in onomastics form an integral system therewith. Thus, having analyzed the current trend of studying proper names system from the cultural and pragmatic point of view, the authors came to the following conclusions:

- In cognitive structures forming communicative competence of great importance are proper names which to the maximum extent embody the cultural and historical experience of the nation.

- Onomastic vocabulary is formed of signs and symbols which can be deciphered and described. Onomastic space, being a significant element in the system of language and culture, contributes to the comprehension of national culture of the given ethnic group.

- Onomastic units are an important part of precedent-setting phenomena. Precedent-setting proper names represent standard ideas generated in the linguistic and cultural community with respect to certain situations and qualities and are used to appeal to extralinguistic knowledge of native speakers.

- Informational and pragmatic transparency of precedent-setting proper names facilitates its decryption and eliminates the need to input a wide explanatory context.

- The complex and multifaceted system of onomastic vocabulary requires researchers to divide it both by denotative correlation (anthroponimics, toponymy, ergonymy and so on), and by the areas of use (real, aesthetic etc).

- Onomastic vocabulary naturally refers to the culture-specific concepts (non-equivalent vocabulary). When transferring allusive culture-specific concepts in the target language, of paramount importance is popularity of the source of association contained in these names with native speakers.

\section{Conclusion}

As a result of the analysis performed the factors have been identified that led to the formation of onomastic pattern of Pavlodar region and the manifestation of specific regional features of the sphere of proper name concepts: Specific mental views towards human reflecting the main spiritual and axiological views, climatic factors (flora and fauna, space-forming role of the territory, a way of habitation of the territory depending on the time and place of settlement.

All this, in the end, allowed the authors of the article to describe the cognitive specifics of onomastic representation in the language and provide the part of the conceptual system that is represented by proper name units existing in the study area. Cognitive models and linguistic mechanisms of onomastic representation identified and described in the article allowed to confirm and develop some of the provisions of cognitive onomastics, in particular the provisions on that a proper name can represent a lot of cognitive structures. Formation of regional sphere of proper name concepts is closely linked to the composition of the onomastic categories which may vary considerably from one region to another. At the same time the differences between the onomastic categories depend on differences that underlie the onomastic concepts, as well as on the levels of conceptualization in onomastics.

The complete analysis of the issue of cognitive description of proper names is limited in this article because of the scale of the described research. Therefore, further authors' work will be continued and developed in the course of research aimed at describing the overall cultural landscape of the city.

\section{Acknowledgement}

The article was supported by the Ministry of Education and Science of the Republic of Kazakhstan (Contract No. 290 dated 12.02.2015) under program "Basic and applied research in the humanities".

\section{References}

1. Fillmore C. Frame semantics. In: Fillmore C, editor. Linguistics in the morning calm. The Linguistic Society of Korea. Seoul: Hanshin; 1982.

2. Grady JE. A Metaphor. In: The oxford handbook of cognitive linguistics. In: Geeraerts D, Cuyckens H, editors. New York: Oxford University Press; 2007.

3. Croft W, Cruse A. Cognitive Linguistics. Cambridge University Press; 2005.

4. Evans V, Green M. Cognitive Linguistics. Edinburgh: Edinburgh University Press; 2006.

5. Evans V. A glossary of cognitive linguistics. Salt Lake City: 
The University of Utah Press; 2007.

6. Cienki A. Frames, idealized cognitive models, and domains. In: Geeraerts D, Cuyckens H, editors. The Oxford Handbook of Cognitive Linguistics. New York: Oxford University Press; 2007.

7. Clausner T, Croft W. Domains and image schemas. Cognitive Linguistics. Berlin, New York: Walter de Gruyter. 1999; 10(1):1-31.

8. Geeraerts D. Introducing cognitive linguistics In: Geeraerts D, Cuyckens H, editors. The Oxford Handbook of Cognitive Linguistics. New York: Oxford University Press; 2007.

9. Nerlich B, Clarke D. Cognitive linguistics and the history of linguistics. In: Geeraerts D, Cuyckens H, editors. The Oxford Handbook of Cognitive Linguistics. New York: Oxford University Press; 2007.

10. Taylor JR. Cognitive Grammar. New York: Oxford University Press Inc; 2002.

11. Johnson M. The body in the mind: The bodily basis of meaning, imagination, and reason. Chicago: University of Chicago Press; 1987.

12. Lakoff G. Linguistic gestalts. Chicago Linguistic Society; 1977.

13. Lakoff G, Johnson M. Metaphors we live by. Chicago: The University of Chicago Press; 1980.

14. Lakoff G. Women, fire and dangerous things. Chicago: Uni- versity of Chicago Press; 1987.

15. Fauconnier G. Frames, mental spaces. In: Geeraerts D, Cuyckens H, editors. The Oxford Handbook of Cognitive Linguistics. New York: Oxford University Press; 2007.

16. Evans V. Review: Oxford handbook of cognitive linguistics. In: Geeraerts D, Cuyckens H, editors. Journal of Linguistics. Cambridge University Press; 2009.

17. Sweetser E. Compositionality and blending: Semantic composition in a cognitive realistic framework. In: Janssen $\mathrm{T}$, Redeker G, editors. Cognitive Linguistics: Foundations, Scope, and Methodology. Berlin, New York: Walter de Gruyter; 1999.

18. Langacker R. Foundations of cognitive grammar. Theoretical Prerequisites. Stanford, CA: Stanford University Press; 1987.

19. Oakley T. Image schemas. In: Geeraerts D, Cuyckens H, editors. The Oxford Handbook of Cognitive Linguistics. New York: Oxford University Press; 2007.

20. Pantner K, Thornburg L. Metonymy. In: The Oxford Handbook of Cognitive Linguistics. Geeraerts D, Cuyckens H, editors. New York: Oxford University Press; 2007.

21. Suyunova GS, Andryuchshenko OK, Tokatova LE, Garanina EP. Methodical tools of philological urbanistics. Mediterranean Journal of Social Sciences. 2015 Sep; 6(5):258-63. 